\title{
Relationship between Helicobacter pylori Infection and Gastrointestinal Symptoms in Children C Tuna-Kirsaclioglu ${ }^{1}$, B Cuhaci-Cakir², ZG Altun², M Kizilgun ${ }^{3}$
}

\begin{abstract}
Objective: We aimed to examine the relationship between Helicobacter pylori $(H$. pylori) infection and gastrointestinal symptoms, and the efficacy of eradication treatment.

Methods: A retrospective chart review was carried for children (5-18 years old) who underwent a ${ }^{14} \mathrm{C}$-urea breath test $\left({ }^{14} \mathrm{C}\right.$-UBT $)$ for $H$. pylori infection. Pre- and post-treatment ${ }^{14} \mathrm{C}$-UBT results, gastrointestinal symptoms, $H$. pylori eradication protocol and treatment consistency were noted.

Results: At presentation, out of 537 patients (65.2\% girls), $43.9 \%$ had ${ }^{14} \mathrm{C}$-UBT positivitiy. The frequency of heartburn, acid regurgitation and halitosis $(p=0.001, p=0.006$, and $p=0.03$ respectively) were significantly high in ${ }^{14} \mathrm{C}$-UBT $(+)$ patients, frequency of epigastric pain $(\mathrm{p}<0.0001)$ was significantly high in ${ }^{14} \mathrm{C}-\mathrm{UBT}(-)$ patients at presentation. ${ }^{14} \mathrm{C}-\mathrm{UBT}(+)$ patients were treated with amoxicillin + lansoprazole + clarithromycin $(66.1 \%) /$ metranidazole (33.9\%). After eradication treatment control ${ }^{14} \mathrm{C}$-UBT were negative in $62.5 \%$ of patients treated with the metranidazole, compared with $47.4 \%$ of patients treated with the clarithromycin protocol $(p=0.03)$. After eradication treatment, frequency of gastrointestinal symptoms (except feeling of hunger) were significantly decreased regardless of treatment success $(p<0.0001)$. The frequency of total gastrointestinal symptoms $(p<$ $0.0001)$, epigastric pain $(\mathrm{p}<0.0001)$, epigastric burning $(\mathrm{p}=0.003)$, heartburn $(\mathrm{p}=0.002)$, acid regurgitation $(\mathrm{p}$ $=0.006)$, nausea $(p=0.001)$, halitosis $(p=0.02)$, early satiety $(p=0.02)$ were significantly reduced in patients with control ${ }^{14} \mathrm{C}$-UBT (-).
\end{abstract}

Conclusion: $H$. pylori eradication, or the attempt to eliminate $H$. pylori, reduces gastrointestinal symptoms in $H$. pylori-infected children.

Keywords: Children, dyspepsia, helicobacter pylori, teatment

From: ${ }^{1}$ Department of Pediatric Gastroenterology, Hepatology and Nutrition, Turkish Republic Health Ministry, Ankara Child Health Diseases, Haematology Oncology Training and Research Hospital, Ankara, Turkey.

2 Department of Pediatrics, Turkish Republic Health Ministry, Ankara Child Health Diseases, Haematology Oncology Training and Research Hospital, Ankara, Turkey.

${ }^{3}$ Department of Biochemistry, Turkish Republic Health Ministry, Ankara Child Health Diseases, Haematology Oncology Training and Research Hospital, Ankara, Turkey.

Correspondence: Dr C Tuna-Kırsaclıglu, Turkish Republic Health Ministry, Ankara Child Health Diseases Haematology Oncology Training and Research Hospital, Ankara, 06800, Turkey, E-mail: ceytun@yahoo.com 


\section{INTRODUCTION}

Helicobacter pylori (H pylori) is one of the most common bacterial pathogens in humans and is acquired mainly during childhood. The prevalence of $H$. pylori infection is still common in developing/undeveloped countries. It can persist for a life time, and chronic infection is nearly always accompanied by chronic active gastritis. H. pylori infection is usually asymptomatic particularly in children, but may cause serious diseases, such as peptic ulcer disease, noncardiac gastric adenocarcinomas, and gastric mucosa-associated lymphoid tissue lymphomas, especially in adults $(1,2)$. There have been conflicting reports on the relationship between $H$. pylori infection and gastrointestinal symptoms in children and adults. Also the resolution of dyspeptic symptoms after a successful H. pylori eradication remains controversial. Also relation of healing of mucosa after eradication or suppression of acid-related symptoms by proton pump inhibitors (PPIs), is debatable (2-11). We aimed to examine the relationship between gastrointestinal symptoms and $H$. pylori infection at presentation and after eradication treatment.

\section{SUBJECTS AND METHODS}

A retrospective chart review was carried out in 1850 patients who underwent a ${ }^{14} \mathrm{C}$-urea breath test $\left({ }^{14} \mathrm{C}\right.$-UBT $)$ for the detection of $H$. pylori infection. These patients primarily admitted or they were referred to our paediatric gastroenterology outpatient clinic after ${ }^{14} \mathrm{C}$-UBT performed between January 2011 and January 2013. Age, gender, symptomatology, and ${ }^{14}$ C-UBT results at diagnosis were noted by the same observer. Also the records of the ${ }^{14} \mathrm{C}$-UBT positive patients were reviewed for the given randomised ampirical treatment protocol, treatment consistency, symptomatology, and post-treatment ${ }^{14} \mathrm{C}$-UBT results by the same observer. Epigastric pain, epigastric burning, heartburn, acid regurgitation, nausea, vomiting, recurrent abdominal pain (RAP), early satiety, halitosis, and frequent feeling of hunger were taken into account in the 
symptomatology. Localised pain sensation in the epigastric region was considered as epigastric pain. Localised burning sensation in the epigastric region, not radiated up towards the throat was considered as epigastric burning. If the burning sensation was in the chest, radiated up towards to thorat was considered heartburn.

A sudden regurgitation of acid gastric content was considered as acid regurgitation. Inability to finish a normal meal was considered as early satiety (12). Halitosis was defined if patient complaint of an unpleasant or offensive odour emanating from the oral cavity (6). Recurrent abdominal pain was defined if abdominal pain was present for at least 3 months, at least 3 episodes, severe enough to affect child's activity (13). The 'improvement' of a symptom was defined, if only there was a complete resolution of the symptom after eradication treatment. ${ }^{14}$ C-UBT was performed with Heliprobe ${ }^{\circledR}$ system (Kibion, Upsala, Sweden).

The study was approved by the Ethics Committee of the Turkish Republic Health Ministry, Ankara Child Health Diseases, Haematology Oncology Training and Research Hospital (2014/023 protocol number), Ankara, Turkey. Of the 1850 patient records, 537 patients (350 girls, $65.2 \%$ ) met the following criteria for inclusion in the study: 1) 5-18 years of age, 2) if at least one of the above gastrointestinal symptoms was present for at least 2 months, 3) not treated with antimicrobial drugs or acid-suppressive drugs for at least 1 month prior to the $\left.{ }^{14} \mathrm{C}-\mathrm{UBT}, 4\right)$ naïve for $H$. pylori eradication treatment, 5) if treatment protocol consisted of lansoprazole $(1-2 \mathrm{mg} / \mathrm{kg} /$ day, maximum $2 \times 30 \mathrm{mg} /$ day $)+$ amoxicillin $(50$ $\mathrm{mg} / \mathrm{kg} /$ day, maximum $2 \mathrm{~g} /$ day $)+$ metranidazole $(15 \mathrm{mg} / \mathrm{kg} / \mathrm{day}$, maximum $1 \mathrm{~g} / \mathrm{day})$ or clarithromycin (15-20 mg/kg/day, maximum $1 \mathrm{~g} / \mathrm{day})$ for 14 days, twice daily, 6) if symptomatology was noted after treatment, 7) if control ${ }^{14} \mathrm{C}$-UBT were performed at least 1 months after completing the eradication treatment. Children were excluded from the study if 1) they had a previously known peptic ulcer disease, or no gastrointestinal complaints at presentation, 2) treatment protocol did not include the drugs above 3) eradication treatment was 
discontinued or improperly used, 4) after eradication treatment a control ${ }^{14} \mathrm{C}$-UBT wasn't performed, 5) control ${ }^{14} \mathrm{C}$-UBT were performed less than 1 month or more than 2 months after completing eradication treatment.

\section{Statistical analyses}

Statistical analyses were performed using SPSS software (ver. 17.0). Results are presented as means \pm SDs with descriptive statistics. The Student's unpaired $t$-test was used as appropriate. When the variances were unequal or the distributions not normal, the Mann-Whitney U-test was used. The significance level was set at $\mathrm{P}<0.05$.

\section{RESULTS}

Mean age of 537 patients (65.2\% girls), who underwent the ${ }^{14} \mathrm{C}$-UBT, was $11.6 \pm 3.3$ (range 518) years old. Among 537 patients, $236(43.9 \%)$ were ${ }^{14} \mathrm{C}$-UBT (+) at presentation. There were $159(67.4 \%)$ girls among the ${ }^{14} \mathrm{C}$-UBT $(+)$ patients and $191(63.5 \%)$ girls among the ${ }^{14} \mathrm{C}$-UBT (-) patients. There was no gender difference between ${ }^{14} \mathrm{C}-\mathrm{UBT}(+)$ and ${ }^{14} \mathrm{C}-\mathrm{UBT}(-)$ patients at presentation $(\mathrm{p}>0.05) .{ }^{14} \mathrm{C}$-UBT $(+)$ patients $[12 \pm 3.3$ (range, $5-17.5)$ years] were older than ${ }^{14} \mathrm{C}$-UBT (-) patients $[11.4 \pm 3.4$ (range, $5-18)$ years $]$ at presentation $(\mathrm{p}=0.03)$.

In Table 1, the gastrointestinal symptoms of patients are given based on the ${ }^{14} \mathrm{C}$-UBT results at presentation. Epigastric pain were more frequently observed in ${ }^{14} \mathrm{C}$-UBT (-) patients as compared with in ${ }^{14} \mathrm{C}$-UBT $(+)$ patients $(\mathrm{p}<0.0001)$. Heartburn, acid regurgitation and halitosis were more frequently observed in ${ }^{14} \mathrm{C}$-UBT $(+)$ patients as compared with in ${ }^{14} \mathrm{C}$-UBT (-) patients $(\mathrm{p}=0.001, \mathrm{p}=0.006, \mathrm{p}=0.03$ respectively). Nausea, vomiting, epigastric burning, early satiety, recurrent abdominal pain (RAP), and a frequent feeling of hunger did not differ between ${ }^{14} \mathrm{C}$-UBT (-) and ${ }^{14} \mathrm{C}-\mathrm{UBT}(+)$ patients ( $\mathrm{p}>0.05$; Table 1$)$. 
All ${ }^{14}$ C-UBT $(+)$ patients $(n=236)$ were administered an eradication protocol: 156 $(66.1 \%)$ patients were treated with amoxicillin + clarithromycin + lansoprazole and 80 patients $(33.9 \%)$ with amoxicillin + metranidazole + lansoprazole. No difference was found in age or gender between treatment protocols at presentation $(\mathrm{p}=0.34$ and 0.25 , respectively).

Regardless of the protocol, 124 of 236 (52.5\%) patients were ${ }^{14}$ C-UBT (-) after treatment. Treatment success did not differ by age and gender $(p=0.07,0.5$, respectively). Fifty $(62.5 \%)$ patients treated with the metranidazole protocol had negative control ${ }^{14} \mathrm{C}$-UBT after eradication treatment, compared with $74(47.4 \%)$ patients treated with the clarithromycin protocol $(\mathrm{p}=$ $0.03)$.

All gastrointestinal symptoms were compared before and after the eradication treatments, as shown in Table 2. After the eradication treatment, regardless of treatment success, $117(49.5 \%)$ patients were still symptomatic, but frequency of total gastrointestinal symptoms were significantly decreased $(\mathrm{p}<0.0001)$. Frequency of epigastric pain, epigastric burning, heartburn, acid regurgitation, nausea, vomiting, RAP, early satiety, and halitosis were reduced significantly as shown in Table 2.

After eradication treatment, the frequency of total gastrointestinal symptoms were decreased significantly in ${ }^{14} \mathrm{C}$-UBT (-) patients compared with the ${ }^{14} \mathrm{C}$-UBT $(+)$ patients $(\mathrm{p}<$ 0.0001). Frequency of epigastric pain, epigastric burning, heartburn, acid regurgitation, early satiety, halitosis and nausea were significantly reduced in ${ }^{14} \mathrm{C}-\mathrm{UBT}(-)$ patients as shown in Table 3.

\section{DISCUSSION}


In our study, H.pylori infection was found $43.9 \%$ of the children who had gastrointestinal symptoms. After eradication treatment, frequency of gastrointestinal symptomps were reduced significantly regardless of the treatment success. Nearly half of the infected children were resistant to the given eradication treatment. The frequency of gastrointestinal symptoms were significantly reduced with successful eradication.

Chronic $H$. pylori-associated gastritis is generally asymptomatic, particularly in children $(2,14)$. Symptomatic diseases associated with $H$. pylori infection generally arise mainly in adults from long-term infection (14). H. pylori infection may cause dyspeptic symptoms through several mechanisms, such as increased gastric acid secretion, persistent and active inflammation of the gastric mucosa, and post-infective motility changes in the gastrointestinal tract, elevated fasting and postprandial levels of serum gastrin, and decreases in somatostatin secretion (14).

There is conflicting evidence for an association between gastrointestinal symptoms and H. pylori infection in both children and adults (2-11, 15-17). Carvalho et al.(10) reported no differences among the rates of symptoms between $H$. pylori-infected and non-infected children. Also, Ozen et al.(18) reported that $H$. pylori-infected children did not complain much more than others of abdominal pain or dyspepsia. Spee et al.(8) found no evidence of any relationship of RAP, nausea, halitosis, dyspepsia, regurgitation with H. pylori infection in children in a metaanalysis of 38 studies. However, Daugule et al.(11) reported a higher prevalence of $H$. pylori infection in children with gastrointestinal symptoms compared with asymptomatic children. In the meta-analysis of Spee et al.(8) an association between $H$. pylori infection and both vomiting and upper abdominal pain was found in referred children (but not in children who were seen in primary care). In our study, halitosis, acid regurgitation and heartburn were more prevalent among $H$. pylori-infected patients at presentation, but epigastric pain was more prevalent in 
${ }^{14}$ C-UBT (-) patients. There was no difference in RAP, nausea, vomiting, early satiety, or the frequent feeling of hungry prevelance between in ${ }^{14} \mathrm{C}$-UBT (-) and (+) patients at presentation.

The resolution of dyspeptic symptoms due to successful $H$. pylori eradication also remain controversial in both children and adults $(16,17)$. It has been reported that the 'active' component (polymorphonuclear leucocyte infiltration) of gastritis recovers quickly and completely following bacterial eradication, but lymphocytic infiltrate in the gastric mucosa may persist for several months or even years (19). It has been suggested that these cells can cause alterations in gastric mucosal function by production of different cytokines. After bacterial eradication, it may take at least 6-12 months for the gastric mucosa to normalize (20). Ashon et al.(7) reported bacterial eradication had no effect on gastrointestinal symptoms, such as abdominal pain, heartburn and regurgitation, hunger pain, nausea, sensation of fullness, burping, or bloating in children. On the other hand, Uc and Chang (9) reported a clear improvement in dyspeptic symptoms after successful eradication in children. Ozcay et al.(3) reported that abdominal pain and dyspeptic symptoms were reduced or completely resolved in $75.7 \%$ of children after successful eradication.

A relationship between gastric acid output and improvement of dyspeptic symptoms following $H$. pylori treatment has been reported (17). Also, increased gastric acid secretion associated with $H$. pylori infection, may be suppressed by proton pump inhibitors (PPIs), and acid-related dyspeptic symptoms may be relieved in attempts to eliminate H. pylori (17).

In our study frequency of total gastrointestinal symptoms (except the feeling of frequent hunger) were significantly decreased after eradication treatment regardless of treatment success. This may be related to the improvement of acid-related dyspeptic symptoms due to PPI treatment. Also, the frequency of total gastrointestinal symptoms were found to be reduced significantly in patients who underwent successful $H$. pylori eradication. Epigastric pain and 
burning, nausea, acid regurgitation, halitosis, heartburn, and an early feeling of satiety were significantly improved with successful eradication.

No relationship has been reported previously between $H$. pylori infection and RAP, and screening for $H$. pylori is not recommended in children with RAP $(1,8)$. In our study RAP was not related to $H$. pylori infection at presentation, and also after a successfull eradication no significant improvement was seen in RAP. Regardless of treatment success, the frequency of patients with RAP reduced after eradication treatment, this may be due to use of PPIs or antibiotics.

The relationship between $H$. pylori infection and gastro-oesophageal reflux disease (GERD) remains a matter of controversy. Both aggravation and recovery of oesophagitis after H. pylori treatment have been reported in adults (21-24). In children, any association between H. pylori infection and GERD also remains controversial. No association, a positive correlation, and protection against GERD have all been reported (22-24). In our study, we found that frequency of acid regurgitation and heartburn were significantly higher in H. pylori (+) patients, and both were reduced after eradication treatment and also after a successful eradication. Unfortunately to establish a precise relationship between GERD and H.pylori due to these results wouldn't be appropriate, because endoscopic, histopathological and $\mathrm{pH}$ monitarisation findings weren't included to the study.

In previous reports, a possible link between H.pylori infection and halitosis has been postulated. Especially after a successful $H$. pylori eradication, improvement of halitosis has been reported $(6,25,26)$. In our study, halitosis found to be related with H.pylori infection and improved with H.pylori eradication. But definining of halitosis due to patients' complaints, inspite of an objective method as gas chromotography which evaluates volatile sulfur compounds in breath was a limiting factor in our study. 
In developing countries, prevelance of $H$. pylori infection is still common. In Turkey $H$. pylori infection was diagnosed in $50-56 \%$ of 'healthy' children by using the ${ }^{13} \mathrm{C}-\mathrm{UBT}$ (18). Also, eradication rates remain low in developing countries (approximately \%50) $(1,17)$. Regardless of the treatment protocol, treatment success was $52.5 \%$ in our study similar to the previous reports. Eradication rates may differ with the given treatment protocol due to antibiotic resistance. A recent review of primary antimicrobial resistance in $H$. pylori in Turkey demonstrated resistance rates to amoxicillin, clarithromycin, and metranidazole of $0.97 \%$, $24.8 \%$, and $33.7 \%$, respectively (27). In previous years, clarithromycin resistance rate was reported to be $18-22 \%$ in children $(3,28)$, but recent studies demonstrated an increased clarithromycin resistance rates $(42-53 \%)$ in our country $(29,30)$. In our study, primary clarithromycin resistance rate was $52.6 \%$ similar to the recent reports. The high resistance rates to clarithromycin in our country may be due to the common and uncontrolled use of clarithromycin in children. Primary metranidazole resistance rate of $37.5 \%$, and we found metranidazole was more effective than clarithromycin in eradication of $H$. pylori.

The study limitations were as following; 1) being a retrospective study, 2) upper gastrointestinal endoscopy, histopathologic examination, H.pylori culture didn't included to the study, 3) a symptom rating scale to compare the severity of pre- and post-treatment symptoms didn't used because of reviewing the records. But we tried to minimize these limitations as following; 1) we considered the 'improvement' of any symptom to be complete resolution of the symptom. If the symptom was merely reduced, or reduced immediately after treatment but again relaps, it was not defined as resolution 2) symptomatology was reviewed by the same observer. 


\section{CONCLUSION}

In our study nearly half of the children with gastrointestinal complaints had $H$. pylori infection and nearly half of the infected children were resistant to eradication treatment. Not only a successful eradication, but also attempt to eliminate $H$. pylori resulted in a significant reduction of gastrointestinal symptoms. 


\section{REFERENCES}

1. Koletzko S, Jones NL, Goodman KJ, Gold B, Rowland M, Cadranel S et al. Evidencebased guidelines from ESPGHAN and NASPGHAN for Helicobacter pylori infection in children. J Pediatr Gastroenterol Nutr 2011; 53: 230-43.

2. Sierra MS, Hastings EV, Goodman KJ. What do we know about benefits of H. pylori treatment in childhood? Gut Microbes 2013; 4: 549-67.

3. Ozcay F, Kocak N, Temizel IN, Demir H, Ozen H, Yuce A et al. Helicobacter pylori infection in Turkish children: comparison of diagnostic tests, evaluation of eradication rate, and changes in symptoms after eradication. Helicobacter 2004; 9: 242-8.

4. Gisbert JP, Cruzado AI, Garcia-Gravalos R, Pajares JM. Lack of benefit of treating Helicobacter pylori infection in patients with functional dyspepsia: randomized oneyear follow-up study. Hepatogastroenterology 2004; 51: 303-8.

5. McColl KE, El-Nujumi A, Murray LS, El-Omar EM, Dickson A, Kelman AW et al. Assessment of symptomatic response as predictor of Helicobacter pylori status following eradication therapy in patients with ulcer. Gut 1998; 42: 618-22.

6. Katsinelos P, Tziomalos K, Chatzimavroudis G, Vasiliadis T, Katsinelos T, Pilpilidis I, et al. Eradication therapy in Helicobacter pylori-positive patients with halitosis: longterm outcome. Med Princ Pract 2007; 16: 119-23.

7. Ashorn M, Rago T, Kokkonen J, Ruuska T, Rautelin H, Karikoski R. Symptomatic response to Helicobacter pylori eradication in children with recurrent abdominal pain: double blind randomized placebo-controlled trial. J Clin Gastroenterol 2004; 38: 64650.

8. Spee LA, Madderom MB, Pijpers M, van Leeuwen Y, Berger MY. Association between Helicobacter pylori and gastrointestinal symptoms in children. Pediatrics 2010; 125: e651-69. 
9. Uc A, Chong SK. Treatment of Helicobacter pylori gastritis improves dyspeptic symptoms in children. J Pediatr Gastroenterol Nutr 2002; 34: 281-5.

10. Carvalho MA, Machado NC, Ortolan EV, Rodrigues MA. Upper gastrointestinal histopathological findings in children and adolescents with nonulcer dyspepsia with Helicobacter pylori infection. J Pediatr Gastroenterol Nutr 2012; 55: 523-9.

11. Daugule I, Rumba I, Alksnis J, Ejderhamn J. Helicobacter pylori infection among children with gastrointestinal symptoms: a high prevalence of infection among patients with reflux oesophagitis. Acta Paediatr 2007; 96: 1047-9.

12. Talley NJ, Phung N, Kalantar JS. ABC of the upper gastrointestingal tract: Indigestion: when is it functional? BMJ 2001; 323: 1294-7.

13. Apley J, Naish N. Recurrent abdominal pains: a field survey of 1,000 school children. Arch Dis Child 1958; 33:165-70.

14. Potamitis GS, Axon AT. Helicobacter pylori and nonmalignant diseases. Helicobacter 2015; 20: $26-9$.

15. Zullo A, Hassan C, De Francesco V, Repici A, Manta R, Tomao S et al. Helicobacter pylori and functional dyspepsia: an unsolved issue? World J Gastroenterol 2014; 20: $8957-63$.

16. Lan L, Yu J, Chen YL, Zhong YL, Zhang H, Jia CH et al. Symptom-based tendencies of Helicobacter pylori eradication in patients with functional dyspepsia. World $\mathbf{J}$ Gastroenterol 2011; 17: 3242-7.

17. Sodhi JS, Javid G, Zargar SA, Zhong YL, Zhang H, Jia CH et al. Prevalence of Helicobacter pylori infection and the effect of its eradication on symptoms of functional dyspepsia in Kashmir, India. J Gastroenterol Hepatol 2013; 28: 808-13. 
18. Ozen A, Ertem D, Pehlivanoglu E. Natural history and symptomatology of Helicobacter pylori in childhood and factors determining the epidemiology of infection. J Pediatr Gastroenterol Nutr 2006; 42: 398-404.

19. Dixon MF, Genta RM, Yardley JH, Correa P. Classification and grading of gastritis. The updated Sydney system. international workshop on the histopathology of gastritis, Houston 1994. Am J Surg Pathol 1996; 20: 1161-81.

20. Fock KM. Functional dyspepsia, H. pylori and post infectious FD. J Gastroenterol Hepatol 2011; 26: 39-41.

21. Schwizer W, Fox M. Helicobacter pylori and gastroesophageal reflux disease: a complex organism in a complex host. J Pediatr Gastroenterol Nutr 2004; 38: 12-5.

22. Moon A, Solomon A, Beneck D, Cunningham-Rundles S. Positive association between Helicobacter pylori and gastroesophageal reflux disease in children. J Pediatr Gastroenterol Nutr 2009; 49: 283-8.

23. Emiroglu HH, Sokucu S, Suoglu OD, Gulluoglu M, Gokce S. Is there a relationship between Helicobacter pylori infection and erosive reflux disease in children? Acta Paediatr 2010; 99: 121-5.

24. Abdollahi A, Morteza A, Khalilzadeh O, Zandieh A, Asgarshirazi M. The role of Helicobacter pylori infection in gastro-oesophageal reflux in Iranian children. Ann Trop Paediatr 2011; 31: 53-7.

25. Yilmaz AE, Bilici M, Tonbul A, Karabel M, Dogan G, Tas T. Paediatric halitosis and Helicobacter pylori Infection. J Coll Physicians Surg Pak 2012, 22: 27-30.

26. Ierardi E, Amoruso A, La Notte T, Francavilla R, Castellaneta S, Marrazza E et al. Halitosis and Helicobacter pylori: a possible relationship. Dig Dis Sci 1998; 43: 27337. 
27 Kocazeybek B, Tokman HB. Prevalence of Primary Antimicrobial Resistance of H. pylori in Turkey: A Systematic Review. Helicobacter 2015; 21:251-60.

28. Kocak N, Saltik IN, Ozen H, Yuce A, Gurakan F. Lansoprazole triple therapy for Turkish children with Helicobacter pylori infections. J Pediatr Gastroenterol Nutr 2001; 32: 614 .

29. Bakir Ozbey S, Ozakin C, Keskin M. [Antibiotic resistance rates of Helicobacter pylori isolates and the comparison of E-test and fluorescent in situ hybridization methods for the detection of clarithromycin resistant strains]. Mikrobiyol Bul 2009; 43: 227-34.

30. Tumgor G, Baran M, Cakir M, Yuksekkaya HA, Aydogdu S. Comparison of standard and standard plus vitamin E therapy for Helicobacter pylori eradications in children. Turk J Gastroenterol 2014; 25: 99-103.

Table 1: Symptoms of patients at diagnosis with respect to the ${ }^{14} \mathrm{C}$-urea breath test (UBT). 
Number of patients $(\%)$

\begin{tabular}{|c|c|c|c|}
\hline $\begin{array}{l}\text { Gastrointestinal } \\
\text { symptoms (n: 537) }\end{array}$ & $\begin{array}{l}{ }^{14} \text { C-UBT (-) } \\
\text { (301 patients) }\end{array}$ & $\begin{array}{l}{ }^{14} \text { C-UBT (+) } \\
\text { (236 patients) }\end{array}$ & $\mathrm{P}$ value \\
\hline Epigastric pain & $236(78.4)$ & $144(61)$ & $<0.0001$ \\
\hline Nausea & $145(48.1)$ & $101(42.8)$ & N.S* \\
\hline Acid regurgitation & $79(26.2)$ & $88(37.3)$ & 0.006 \\
\hline Epigastric burning & $46(15.2)$ & $46(19.4)$ & N.S \\
\hline Heartburn & $23(7.6)$ & $39(16.5)$ & 0.001 \\
\hline Vomiting & $43(14.2)$ & $29(12.3)$ & N.S \\
\hline Halitosis & $41(13.6)$ & $49(20.8)$ & 0.03 \\
\hline Early satiety & $28(9.3)$ & $27(11.4)$ & N.S \\
\hline Recurrent abdominal pain & $23(7.6)$ & $22(9.3)$ & N.S \\
\hline Feeling of hunger & $14(4.6)$ & $11(4.7)$ & N.S \\
\hline
\end{tabular}

*N.S Non significant

Table 2: Gastrointestinal symptoms of ${ }^{14} \mathrm{C}$-urea breath test (UBT)-positive patients at presentation and after eradication treatment independent of the control ${ }^{14} \mathrm{C}$-UBT results. 


\begin{tabular}{llll}
\hline Gastrointestinal symptoms & \multicolumn{2}{l}{ Number of patients $(\%)$} & P value \\
& At presentation & Post-treatment & \\
\hline $\begin{array}{l}\text { Total gastrointestinal } \\
\text { Eymptoms }\end{array}$ & $236(89.1)$ & $117(49.5)$ & $<0.0001$ \\
Nausastric pain & $144(61)$ & $72(61.5)$ & $<0.0001$ \\
Epigastric burning & $101(42.8)$ & $42(35.9)$ & $<0.0001$ \\
Acid regurgitation & $46(19.4)$ & $28(11.8)$ & $<0.0001$ \\
Halitosis & $88(37.3)$ & $38(32.4)$ & $<0.0001$ \\
Heartburn & $49(20.8)$ & $27(23)$ & $<0.0001$ \\
Vomiting & $39(16.5)$ & $10(4.2)$ & $<0.0001$ \\
Early satiety & $29(12.3)$ & $3(2.5)$ & $<0.0001$ \\
Recurrent abdominal pain & $22(9.3)$ & $13(11.1)$ & $<0.0001$ \\
Feeling of hunger & $11(4.6)$ & $8(6.8)$ & $<0.0001$ \\
& & $7(5.9)$ & N.S* \\
\hline N.S. N & & & \\
\hline
\end{tabular}

*N.S. Non significant 
Table 3: Gastrointestinal symptoms of patients with respect to control ${ }^{14} \mathrm{C}$-urea breath test (UBT) results after eradication treatment

\section{Number of patients (\%)}

Gastrointestinal $\quad{ }^{14}$ C-UBT (+) (n:112) $\quad{ }^{14}$ C-UBT (-) (n: 124) P value
symptoms

\begin{tabular}{llll} 
Total & $78(85.7)$ & $39(26.8)$ & $<\mathbf{0 . 0 0 0 1}$ \\
gastrointestinal & & & \\
symptoms & & & \\
Epigastric pain & $48(52.7)$ & $24(16.5)$ & $<\mathbf{0 . 0 0 0 1}$ \\
Nausea & $30(33)$ & $12(8.2)$ & $\mathbf{0 . 0 0 1}$ \\
Epigastric burning & $20(22)$ & $8(5.5)$ & $\mathbf{0 . 0 0 3}$ \\
Acid regurgitation & $25(27.4)$ & $13(8.9)$ & $\mathbf{0 . 0 0 6}$ \\
Halitosis & $18(19.7)$ & $9(7.6)$ & $\mathbf{0 . 0 2}$ \\
Heartburn & $7(7.7)$ & $3(2)$ & $\mathbf{0 . 0 0 2}$ \\
Vomiting & $2(2.1)$ & $1(0.6)$ & N.S* \\
Early satiety & $10(11)$ & $3(2)$ & $\mathbf{0 . 0 2}$ \\
Recurrent & $6(6.6)$ & $2(1.3)$ & N.S* \\
abdominal pain & & $3(2)$ & N.S* \\
Feeling of hunger & $4(4.4)$ & & \\
\hline
\end{tabular}

*N.S. Non significant 